AARP INTERNATIONAL THE JOURNAL

VOLUME $11-2018$ EDITION

AARP

Real Possibilities

\title{
Supporting Family Caregivers: It's in Our DNA
}

By Bob Stephen 


\title{
Supporting Family Caregivers: It's in Our DNA
}

\author{
By Bob Stephen
}

O ne of AARP's top priorities is supporting family caregivers - those providing unpaid short-term or longterm care to a parent, spouse, friend or other adult loved one. They help with everyday activities and personal tasks such as transportation, managing finances, scheduling appointments, shopping, bathing, dressing, preparing meals, wound care and/or medication management.

You could say that supporting family caregivers is in our DNA. AARP's founder, Dr. Ethel Percy Andrus, left her high school principal job in 1944 to care for her ailing mother. Then and now, family caregivers have been the backbone of the long-term care system in this country. Of course, much has changed in the last seventy-plus years, thanks to such trends as demographic changes and advances in care. Today there are more than forty million family caregivers in the United States. AARP's Public Policy Institute estimates that the value of the mostly unpaid care provided by family caregivers is over $\$ 470$ billion per year. That's more than total Medicaid spending.

As with previous generations, Baby Boomers will depend on their friends and family to help them stay in their homes and communities as they age (nine in 10 want to do this). Yet demographic shifts mean challenges lie ahead. Based on analysis by AARP's Public Policy Institute, the number of potential family caregivers available for older Americans will drop dramatically in the coming years. From 1990 to 2010 , there were just over seven potential caregivers ages $45-64$ for every person aged $80+$. Over the next 20 years, the number of potential caregivers ages 45-64 will drop to about four for every person aged 80+. And between 2030 and 2050, the number will drop to only about three potential caregivers for every $80+$ person.

So the need to better support family caregivers will only increase with time, spurring AARP to bring the full scope of our enterprise to the issue. This involves our advocacy, wealth of information in all related fields, local resources, and market changing products and services.

AARP's policy and advocacy work in this important area has been highly visible in the last few years. Building off of the AARP Public Policy Institute's Home Alone report, which highlighted how over half of all family caregivers perform complex medical tasks, AARP developed The CARE Act. The model legislation for states basically requires hospitals to record the family caregiver when a patient is admitted, gives the family caregiver notice before discharge, and provide training for any complex medical tasks required. This legislation is now law in 39 states and territories across the country.

Further AARP research shows that, on average, family caregivers spend almost $\$ 7,000$ out of pocket to care for their loved ones. This important finding has led to the introduction of state and federal legislation to provide a tax credit to family caregivers.

Advocacy also serves as a catalyst for greater change beyond policy. The relationships forged in moving legislation - whether with other non-profits, healthcare providers, business and employers, and faith organizations also lead to direct impact on the ground, such as equipping family caregivers with the help and resources they need.

There is no silver bullet available to directly support all family caregivers. Regarding the 40 million+ family caregivers, we often say there are 40 million unique individuals caring for a loved one. Each individual and situation is different given the condition of their loved one, their location, living arrangement, income, age, culture - the list goes on.

Our goal at AARP is to increase the number of family caregivers who receive help when they need it. Today, only about 30 percent of family caregivers access some sort of help. Clearly, there is much work to do.

To craft a strategy to equip family caregivers (and increase that percentage served), we put the family caregiver front and center and listen to them. We have learned that while everyone is unique, there are some common experiences - particularly when caregiving demands first intensify. Caregivers expect AARP to be there for them with specific information in a way that does not add to complexity or fragmentation. Through quantitative research along 


\section{"From 1990 to 2010, there were just over seven potential caregivers ages 45-64 for every person aged $80+$. Over the next 20 years, the number of potential caregivers ages 45-64 will drop to about four for every person aged 80+. And between 2030 and 2050, the number will drop to only about three potential caregivers for every $80+$ person."}

with talking to family caregivers and partners, we have learned that family caregivers want AARP to help them:

- Navigate financial and legal complexity, helping them to understand how to pay for their loved one's care and ensuring legal documents are in place to allow them to care;

- Advocate for their loved one in the health system, regardless of the condition of their loved one, they want to understand how to talk to healthcare providers;

- Keep their loved one safe at home, understanding how to make modifications and learn how to stay connected;

- Understand and navigate the types of services available to their loved one in their community; and

- Find ways to increase life balance, whether managing work, stress, or their health in order to be there for their loved one.

Such insights shape our strategy. We are focusing on core information, developing local and digital channels that show up where caregivers are, and developing relationships with other leading organizations to increase connections to existing information, tools, and services.

Certainly other areas of support and information are needed. The good news, there are organizations that already have existing expertise and trust. That's why AARP's goal is to create seamless connections. We are actively engaging with leading organizations - most of which are also our partners on advocacy - such as the Alzheimer's Association, American Cancer Society, and United Way. As an example, AARP and the Alzheimer's Association have arranged for callers to AARP with Alzheimer's questions to receive a "warm transfer" — that is, a seamless phone connection — to an expert at the Alzheimer's Association.

In spite of all these efforts, the previously mentioned 30 percent figure reminds us that we have a long way to go in terms of reaching people. Producing information and creating resources are certainly critical (particularly if gaps exist), but a major challenge is connecting caregivers to this help. This requires building awareness and showing up where and how caregivers might look (not expecting them to come find us). Family caregivers have told us they want information and help in a variety of formats - paper, digital, in-person — and available in a culturally appropriate manner. They already look to family, friends, healthcare providers, and in some cases faith organizations, and employers for help, so this is where those of us looking to reach family caregivers need to show up. This is our challenge - working with our national and local partners - to truly create an impact.

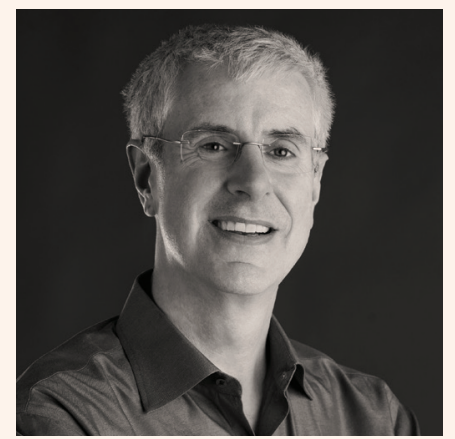

Bob Stephen VICE PRESIDENT CAREGIVING \& HEALTH AARP 
AARP International engages global stakeholders to spark solutions that strengthen communities, protect the vulnerable and enable people around the world to pursue their goals and dreams. Working with governments, civil society and the private sector, we are focused on enhancing the quality of life for people as they age. We serve as the global voice for AARP, a social change organization with a membership of more than 37 million.

THE JOURNAL ONLINE

aarpinternational.org/journal

AARP INTERNATIONAL ONLINE

aarpinternational.org

FACEBOOK

facebook.com/aarpintl

TWITTER

@aarpintl

CONTACT

AARP International

601 E Street, NW

Washington, DC 20049

United States

T +1 2024342398

E international@aarp.org

AARP International: The Journal is a publication of AARP. The views expressed herein do not necessarily represent policies of AARP and should not be construed as endorsements. The mention of a product or service herein is solely for information to our readers and may not be used for any commercial purpose. AARP, which was established in 1958, is a nonprofit, nonpartisan organization with tens of millions of members ages 50 and older. State offices are located in all 50 states, the District of Columbia, Puerto Rico, and the Virgin Islands.

January 2018

()2018, AARP

Reprinting with permission only. 